\title{
DEVELOPMENT OF METHODS AND MEANS OF COMPUTER SIMULATION FOR STUDYING ARC FURNACE ELECTRIC MODES
}

Goal. The purpose of the article is the creation of a three-phase instantaneous coordinates Simulink computer model of the power supply and automatic coordinates control system (ACS) of the DSP-200 type arc furnace electric mode (EM). The model has a convenient interface for changing the structure and parameters of the three-phase arcs power supply system, the structure and laws of the electric mode control system, as well as the stochastic characteristics of parametric and coordinate disturbances. Method. The provisions of the electric circuits theory, experimental study and mathematical and computer simulation in the Simulink system of the MatLAB computing environment were used for the research. Results. A high-precision instantaneous coordinates Simulink-model of the power supply system and electric mode coordinates ACS of the ER DSP-200 furnace was created. This model was used to study the EM and evaluate the performance of the arc furnace during various technological melting periods and with various structures of the automatic control system. Scientific novelty. For the first time, based on a combination of Simulink application library elements and SimPowerSystems standard library blocks of the MatLAB environment a complete high-precision three-phase instantaneous coordinate model of arc furnace DSP-200 power supply system and EM ACS was developed. The developed model has significant advantages in accuracy, performance and features compared to existing ones. Practical value. Possibility to run on the created Simulink-model mathematical experiments on the research of the electric mode coordinates control dynamic indices and electromagnetic compatibility indices of the electric arc furnace and the supply network under the influence of the deterministic and random perturbations. References 11, tables 3, figures 16.

Key words: arc furnace, Simulink computer model, power supply system, automatic control system, electric mode, regulator, dynamic current-voltage arc characteristic, electromechanical circuit.

Цель. Целью статьи является создание трехфазной в мгновенных координатах компьютерной Simulink-модели системы питания и системы автоматического регулирования (САР) координат электрического режсма (ЭР) дуговой сталеплавильной печи типа ДСП-200, которая имеет удобный интерфейс для изменения структуры и параметров системы питания трехфазных дуг, структуры системы и законов управления электрическим режимом, а также стохастических характеристик параметрических и координатных возмущений. Методика. Для проведения исследований использовались положения теории электрических цепей, экспериментальные исследования и математическое и компьютерное моделирование в приложснии Simulink программы Matlab. Результаты. Создана высокоточная компьютерная в мгновенных координатах Simulink-модель системы питания и САР координат ЭР ДСП-200 и с ее использованием проведены исследования ЭР и получены оценки показателей функционирования дуговой печи в различных технологических периодах плавления и при различных структурах системы автоматического управления (САУ). Научная новизна. Впервые на основе сочетания элементов библиотеки приложения Simulink и типовых библиотечных блоков SimPowerSystems программы Matlab составлена трехфазная в мгновенных координатах полная модель системы питания и САУ ЭР дуговой печи ДСП-200, которая имеет значительные преимущества по точности, быстродействию и функциональным возможсностям по сравнению с известными моделями. Практическая ценность. Возможность выполнения на созданной Simulink-модели математических экспериментов по исследованию показателей динамики регулирования координат ЭР и показателей электромагнитной совместимости режимов ДСП и электросети при действии детерминированных и случайных возмущений. Библ. 11 табл. 3, рис. 16.

Ключевые слова: дуговая сталеплавильная печь, компьютерная Simulink-модель, система питания, система автоматического регулирования, электрический режим, регулятор, динамическая вольт-амперная характеристика дуги, электромеханический контур.

Introduction. Arc furnaces are powerful electrotechnological facilities for melting steels and alloys mainly from scrap metal. Considering the considerable installed power and the extremely dynamic asymmetric and non-linear nature of the load, it is not always possible to carry out experimental studies of their modes and parameters of the melting process in the arc furnaces in view of a number of organizational, technical and industrial reasons. Particular difficulties arise when it is necessary to carry out experimental research for various structures of the automatic control system (ACS), for its various parameters, for various circuit changes in the power supply circuit of three-phase arcs, and so on.

Problem definition. One of the approaches to obtaining the indicated information (indicators of dynamics, electrotechnical efficiency and electromagnetic compatibility) is mathematical and computer simulation $[1,2]$. However, the existing mathematical and computer models of processes in the arc furnaces in terms of speed, accuracy of reproduction of modes, functional

capabilities, the convenience of changing the structure, parameters and setting of model experiments do not meet the modern requirements for a comprehensive study of dynamics, electrotechnical efficiency and electromagnetic compatibility.

Review the recent publications. Existing computer models [3, 4] have a complicated and awkward interface for changing the parameters and structure of the ACS of EM and the power supply of the three-phase arcs, the laws of the control of the electric mode, the operative formation of perturbation characteristics with different stochastic characteristics corresponding to the investigated technological stages melting, statistical processing of simulation results in on-line mode that complicates the computer research of the EM of the arc furnace in search of the best solutions for the structure and parameters of the ACS and the laws governing the EM. Some of the known models are used only for the analysis of the process of coordinate change of the EM in

(C) O.Y. Lozynskyi, Y.S. Paranchuk, R.Y. Paranchuk, F.D. Matico 
a power circuit in a power circuit without a closed system of regulating arc lengths in averaged coordinates [5], others have a complicated and awkward interface for changing the structure of the ACS, control laws, indices of parametric and coordinate perturbations, dependencies of dynamic volt-ampere characteristics of arcs, etc. [6-8]. They have peculiar or low accuracy of modes reproduction [5], or limited functional capabilities for setting up and conducting various mathematical experiments [6-8].

Justification of relevance. Therefore, the problem of the creation of new high-precision and highperformance computer models of the power supply system and the ACS of the coordinates of the arc furnaces' EM which takes into account all the main nonlinearities, peculiarities of the changes of parametric and coordinate disturbances in the melting process in which convenient interfaces of the structure change, control laws and parameters of the ACS are implemented, the formulation of mathematical experiments and the statistical processing of the results of research for today is an actual and important scientific and technical task.

The goal of the work is the creation of a threephase in the instantaneous coordinates structural Simulink model of the system of supply of three-phase arcs and the system of automatic control of the electric mode of the arc furnace and the study of the parameters of the dynamics of electrical regimes and indicators of electromagnetic compatibility with its use.

The scientific task is to create a structured Simulink model of the three-phase arc power supply system and an automatic control system for arc furnace electric regime based on the combination of model elements of the Simulink library and the structural blocks SimPowerSystem of the Matlab code.

Structural Simulink model of the power supply system and the ACS of the coordinates of the EM of the DSP-200 furnace. Fig. 1 shows the developed functional circuit of the power supply system of threephase arcs without a zero conductor and a one-circuit system of automatic regulation of coordinates of the EM with a differential law for the formation of a control signal on the displacement of electrodes (automatic adjustment of arc lengths).

On the basis of this functional circuit, a Simulink computer model (Fig. 2) was created which is configured for the parameters of the power supply system, power electrical equipment and arc power regulator of ARDMT-12 type (ACS of the coordinates of the EM) of an arc furnace type DSP-200. The testing of the model was carried out by comparing the dynamics indicators of the development of the working out of deterministic and stationary random disturbances by the length (voltage) of the arc obtained on the operating arc furnace DSP-200 and on the developed its Simulink model under differential control law.

For adequate reproduction in the developed computer model of the real dependencies of the dynamic volt-ampere characteristics (DVAC) of arcs occurring at different technological stages of melting, in the modulus of three-phase arcs of the Simulink model the possibility of realization in the current mathematical experiment is envisaged of one of the four models corresponding to the main technological stages of melting - the linear $u_{a}(t)=R_{a}(t) \cdot i_{a}(t)$ and the nonlinear ones - based on the arc tangent function $u_{a}(t)=2 \cdot E_{a m}(t) \cdot \arctan \left(k \cdot i_{a}(t)\right) / \pi$, on the basis of the differential Cassie equation $\theta \frac{d g_{a}(t)}{d t}=\left(\frac{u_{g}(t)^{2}}{E_{a m}^{2}}\right) g_{a}(t)$ and nonlinear with complex nonlinear functional dependence on the basis of the use of piecewise linear and piecewise nonlinear splines $u_{a}(t)=\Psi\left(i_{a}(t), l_{a}(t)\right)$ with the possibility of reproduction of the hysteresis properties of the arc, ignition peaks, arc extinguishing, etc., where $g_{a}(t), R_{a}(t)$ are the instantaneous arc conductivity and resistance; $E_{a m}$ is the maximum value of anti-EMF of the arc; $\left.u_{a}(t), i_{a}(t), l_{a}(t)\right)$ are the instantaneous arc voltage, current and length, $\Theta_{a}$ is the time constant characterizing the thermal inertia of the arc [9].

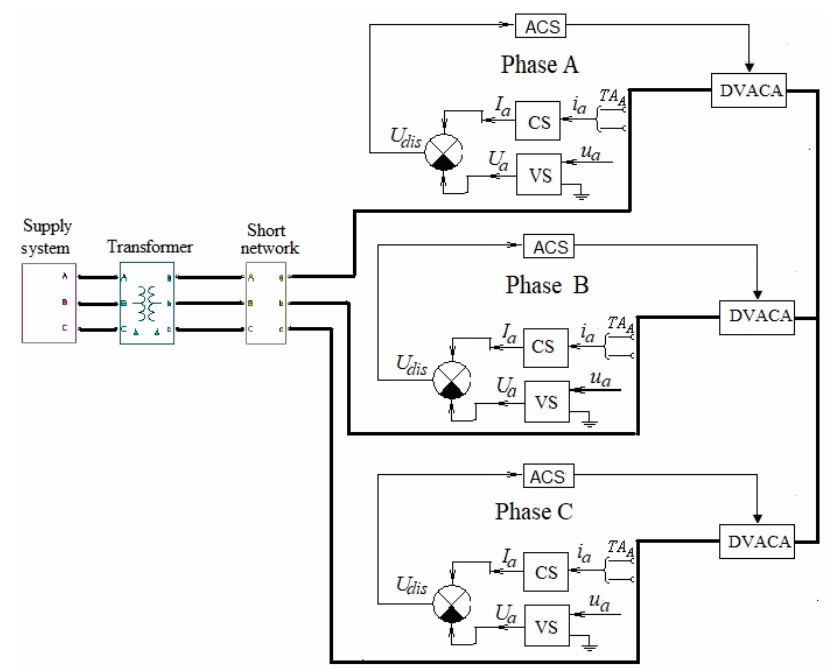

Fig. 1. Functional circuit of the three-phase Simulink model of the power supply system and the ACS of the coordinates of the EM of the DSP-200 furnace

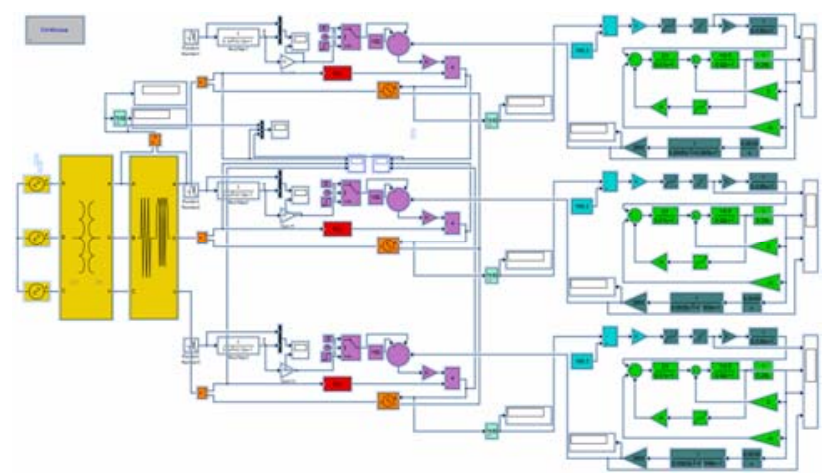

Fig. 2. Structural circuit of the three-phase Simulink model of the power supply system and the ACS of the coordinates of the EM of the DSP-200 arc furnace

The change in the value of the time constant $\Theta_{a}$ in the model can reproduce the conditions of burning arcs at different technological stages of melting, that is, to realize different arcs DVAC (their area characterizes the reactive power of the arc). At the beginning of the melting $\Theta_{a}=0.2 \div 0.5 \mathrm{~ms} ; \Theta_{a}=1 \div 1.5 \mathrm{~ms}$ at the interval of formation of the liquid phase of the melt, and in the periods of oxidation and refining $-\Theta_{a}=3 \div 5 \mathrm{~ms}$. 
The model of the block of three-phase arcs for making the corresponding structural and parametric changes has the potential to reproduce the above types of arcs DVAC which are inherent in different technological stages of melting.

In Fig. 2 elements of the model of the three-phase symmetric electric network (EN), the furnace transformer unit (FTU) and the secondary conductor - short network (SN) of the furnace which represent a model of the power electric circuits of the supply of the three-phase arcs of the arc furnace with the corresponding DVAC indicated in yellow which are collected on the elements of the SimPowerSystems library (red). On these elements the possibility of reproduction of the four types of dynamic arcs DVAC described above which take place at different technological stages of melting is realized.

Voltage sources reproduce the three-phase sinusoidal voltage of the arc furnace power supply network with a frequency of $50 \mathrm{~Hz}$, amplitude $35 \sqrt{2} \mathrm{kV}$ and the angle of shift of 120 electrical degrees. Block «furnace transformer» represents a three-phase transformer with a transformation coefficient $k_{t r}=35000 / 480=72.92$ and power $\mathrm{S}=125 \mathrm{MVA}$.

The block «total impedance» simulates the total resistance of all active resistances of elements of the power supply system of the arcs (choke, transformer, short network and electrode in each phase) which are united in resistance $r_{s s}$, and all their inductive resistances are united in resistance $x_{s s}$.

The red block $I_{a}\left(U_{a}\right)$ reproduces the static internal characteristic of the arc furnace DSP-200 for the appropriate stage of the power furnace transformer.

The orange block is a controlled voltage source whose input-output characteristic is formed by the block $I_{a}\left(U_{a}\right)$ and the perturbation setting block.

Violet blocks from the group of elements of the perturbation setting simulate the deterministic and random perturbations along the arc length which arise during the arc furnace operation at arc gaps at different technological stages of melting. The purpose of this group of blocks is the formation of various time realizations of disturbances along the arc length in the phases of a short furnace network, with the same statistical characteristics that correspond to the investigated technological stages of melting.

Blocks of bright blue color reproduce the model of the block of comparison of input signals of the ACS for realization of the corresponding law of formation of the signal of the EM mismatch. Its output signal is the $U_{d i s}$ mismatch signal, and its «input-output» dependence $U_{d i s}=F\left(U_{a}, I_{a}\right)$ varies according to the investigated law of electric mode control.

Elements of the Simulink model of dark green color simulate the static dependence «input-output» of the block of the formation of a control signal on displacement of the electrode of a particular phase of the furnace. It implements the «zone of insensitivity» $(\delta=2 \ldots 10 \%)$, the gain factor for lifting and lowering the electrodes, limiting the maximum speed $U_{t}^{\max }$ for lifting and $U_{d}^{\max }$ for lowering of the electrodes, reproduces the inertia of the low frequency filter which is connected in each phase at the output of the rectifiers of the current sensor CS and the voltage sensor VS. Fig. 3 shows the static characteristic of the control signal formation block $U_{c}=f\left(U_{d i s}\right)$.

The block «Reducer» serves to convert the angular velocity of the motor reduced to the angular velocity of the gear, into the linear displacement of the electrode and is represented in the Simulink model by a non-linear link of the type «backlash» and the integrating link that simulate the mechanical gear type «gear-rail». The «oscillating link» block reproduces a limited rigidity of the individual elements of the kinematic circuit of the mechanism of moving the electrodes, in particular the vertical column, the horizontal arm of the electrode holder and the electrode itself.

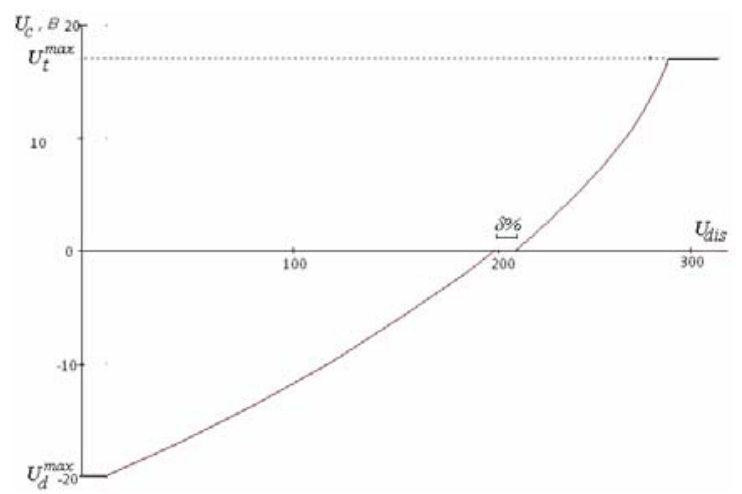

Fig. 3. Dependence «input-output» of the block of formation of the control signal

The group of green elements simulates the electric drive of the mechanism of displacement of the electrode of the ARDM-T-12 type arc power regulator which is assembled according to the circuit «reverse thyristor converter - DC motor» with a nonlinear negative feedback on the current of the armature and a motor negative on speed and with summation of these signals on the input amplifier.

In RMS blocks, the current values of current and arc voltage are continuously calculated in the simulation process by the formula $\operatorname{RMS}(f(t))=\sqrt{\frac{1}{T} \int_{t-T}^{t} f(t)^{2}}$.

In Table 1 experimental results for the DSP-200 furnace which describe the static external characteristics of this furnace $I_{a}\left(U_{a}\right)$ and the dependence of the arcs power $P_{a}\left(U_{a}\right)$ which are reproduced by functional blocks in the model in the power circuit model of the DSP-200 furnace are shown.

In Fig. 4, 5 the model dependences of these two main characteristics of the DSP-200 arc furnace are constructed on the basis of these experimental data.

In Fig. 5 dashed lines show the coordinates of the point of maximum arcs power and arcs power points which corresponds to the steady mode of the furnace at the first stage of the furnace transformer voltage. The coordinates of the point of the steady state (voltage and current of the arc) correspond to the settings of the ARDM-T-12 type arc power regulator on the $U_{\text {set }}$ voltage and the $I_{\text {set }}$ arc current, respectively. 
Table 1

Experimental data for characteristics $I_{a}\left(U_{a}\right)$ and $P_{a}\left(U_{a}\right)$ of the arc furnace DSP-200

\begin{tabular}{|c|c|c|}
\hline$I_{a}, \mathrm{~A}$ & $U_{a}, \mathrm{~V}$ & $P_{a}, \mathrm{~W}$ \\
\hline 70962 & $3.96 \mathrm{E}-06$ & 0.28101 \\
\hline 68808 & 39.39 & 2710347 \\
\hline 65339 & 77.98 & 5095135 \\
\hline 60614 & 115.13 & 6978490 \\
\hline 54723 & 149.99 & 8207903 \\
\hline 47894 & 183.34 & 8780886 \\
\hline 43970 & 198.2 & 8714854 \\
\hline 40800 & 208.5 & 8506800 \\
\hline 33590 & 227.9 & 7655161 \\
\hline 27593 & 241.85 & 6673367 \\
\hline 19392 & 256.72 & 4978314 \\
\hline 14749 & 263.25 & 3882674 \\
\hline 7673 & 271.11 & 2080227 \\
\hline 2877 & 275.2 & 791750.4 \\
\hline 1428 & 276.25 & 394485 \\
\hline 142.7 & 277.08 & 39539.32 \\
\hline 14.27 & 277.14 & 3954.788 \\
\hline 1.4273 & 277.16 & 395.5905 \\
\hline
\end{tabular}

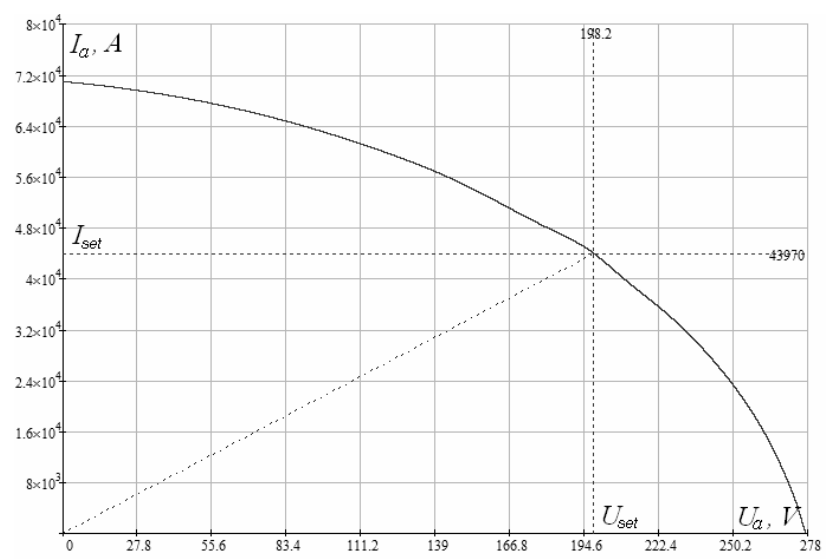

Fig. 4. External characteristic $I_{a}\left(U_{a}\right)$ of the furnace DSP-200

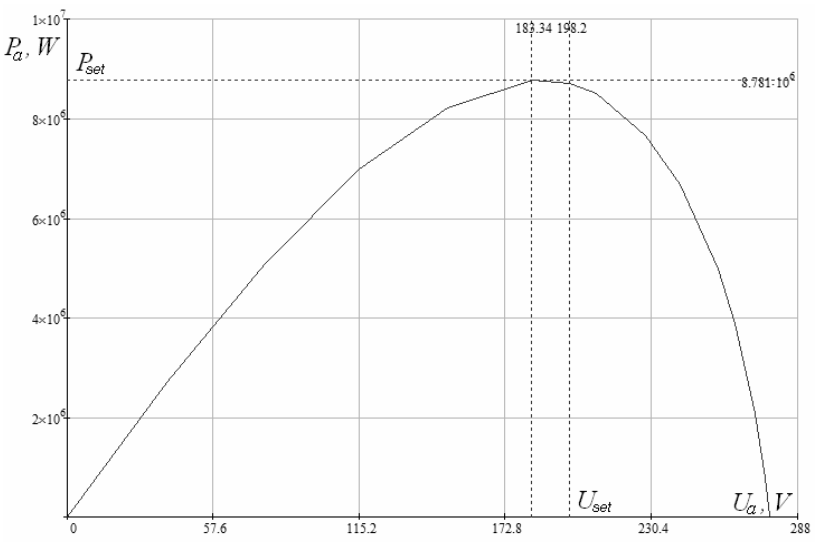

Fig. 5. Power dependences $P_{a}\left(U_{a}\right)$ of the arcs of DSP-200

The Simulink model structural circuit includes a module of the generator of the deterministic (in particular, the extreme ones which cause symmetric or asymmetric by the phases operational short circuits or breakdowns of the arc) and stationary random disturbances along the length of arcs which, according to the stochastic characteristics, correspond to the perturbations acting in the arc gaps in the investigated technological stages. The created Simulink model also includes a module for calculating the integral characteristics of temporal processes of changing the coordinates of the EM and the indicators of electromagnetic compatibility which in a complex manner characterize the efficiency of the control of the modes and the dynamics of coordinates adjustment of the EM of the furnace DSP-200 with the adjusted structure of the ACS for a certain technological stage, the perturbation characteristics and the chosen control laws for the EM.

The study of the accuracy of the created Simulink model was performed on the basis of a comparison of mathematical expectations and dispersion of the processes of the change in the mean-square values of arcs currents $I_{a}(t)$ obtained on the operating arc furnace DSPA-200 and its Simulink model at various technological melting stages. Comparison of their meanings was performed on the basis of the M-criterion of Bartlett [10]. The criterion estimates for the mathematical expectation $t_{M}$ and for the dispersions $t_{D}$ of arcs currents were obtained by formulas (1) and (2) respectively:

$$
\begin{gathered}
t_{M}=\frac{N-k}{k-1} \cdot \frac{\sum_{i=1}^{k} n_{i} \cdot\left(\bar{x}_{i}-\bar{x}\right)^{2}}{\sum_{i=1}^{k} \sum_{j=1}^{n_{i}}\left(x_{i j}-\bar{x}_{i}\right)^{2}} ; \\
t_{D}=\frac{\ln 10}{c}\left[(N-k) \cdot \lg s^{2}-\sum_{i=1}^{k}\left(n_{i}-1\right) \cdot \lg s_{i}^{2}\right] ; \\
c=1+\frac{1}{3 \cdot(k-1)} \cdot\left(\sum_{i=1}^{k} \frac{1}{n_{i}-1}-\frac{1}{N-k}\right) ; \\
s^{2}=\frac{1}{N-k} \cdot \sum_{i=1}^{k}\left(n_{i}-1\right) \cdot s_{i}^{2},
\end{gathered}
$$

where $N=\sum_{i=1}^{k} n_{i}$ is the total data number; $k$ is the number of samples; $n_{i}, i=1,2, \ldots, k$ is the size of the $i$-th sample; $\quad \bar{x}_{i}=\frac{1}{n_{i}} \cdot \sum_{j=1}^{n_{i}} x_{i j}, \quad i=1,2, \ldots, k-$ is the average value of the $i$-th sample; $\bar{x}=\frac{1}{N} \sum_{i=1}^{k} \sum_{j=1}^{n_{i}} x_{i j}$ is the total average value of the aggregate of data; $s_{i}^{2}=\frac{1}{n_{i}-1} \cdot \sum_{j=1}^{n_{i}}\left(x_{i j}-\bar{x}_{i}\right)^{2}$ is the dispersion of the $i$-th sample.

The obtained values of these criteria did not exceed the acceptable (tabular) value of the criterion - 3.84 which was taken for the $5 \%$ level of significance $\alpha$. On the basis of comparison of these estimates, we have obtained confirmation of the achievement of sufficient accuracy of reproduction of the real processes of changing the arcs currents $I_{a}(t)$ in the Simulink model of the arc furnace DSP-200.

Investigation of the dynamics and efficiency of different structures of the ACS of the EM of the DSP200 furnace. In the first stage of the research, the 
simulation of the processes in the electric drive of the mechanism of the displacement of the electrodes (electromechanical system «thyristor converter - motor» (TC-M)) of the ARDM-T-12 type arcs power regulator and the mechanism of electrode displacement (MED) was performed. Their dynamic and static properties significantly affect the parameters of quality of control of arcs lengths (the working out of perturbations along the arcs lengths). Fig. 6 shows a fragment of the general Simulink model of DSP-200 which reproduces the processes of changing the coordinates of the electric drive and the MED in one phase, and Fig. 7 shows obtained on this model dynamical processes of changing the current of the armature $I_{m}(t)$ and the angular velocity $\omega_{m}(t)$ of the MED motor in the deterministic changes of the control signal $U_{c}(t)$ on the input of the thyristor converter.

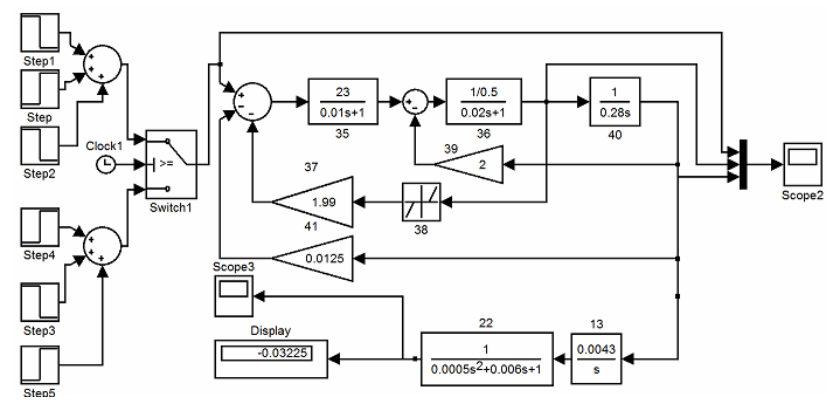

Fig. 6. Simulink-model of the electric drive according to the TC-M circuit of the mechanism of displacement of the electrode of the arcs power regulator ARDM-T-12

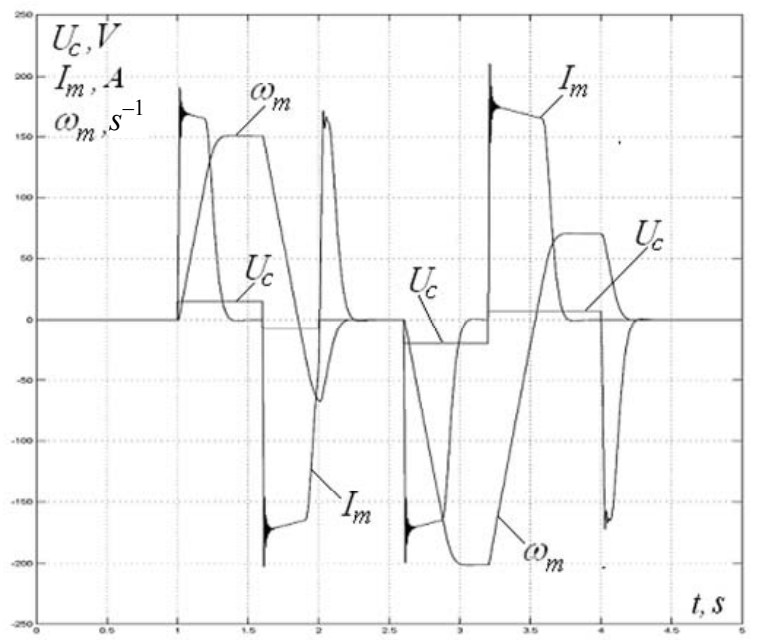

Fig. 7. Dynamics of current $I_{m}(t)$ and motor speed $\omega_{m}(t)$ of MED with a deterministic change in control signal $U_{c}(t)$ of the electric drive of the MED

Fig. 8 shows obtained on the developed Simulink model the temporal dependences of changes of the instantaneous values of the voltage of the secondary winding of the FT $u_{2 p f}(t)$ and the current $i_{a}(t)$ and the voltage $u_{a}(t)$ of the arc in the phase $\mathrm{A}$ in the quasistationary mode of working out of random perturbations in the nonlinear arc DVAC which is described by the function of the arctangent. The given temporal dependences illustrate the effect of the trapezoidal shape of the voltage on the arcs which is observed at the end of the melting of the solid charge on the distortion of the sinusoidal shape of the arc current and the phase voltage of the secondary winding of the furnace transformer unit.

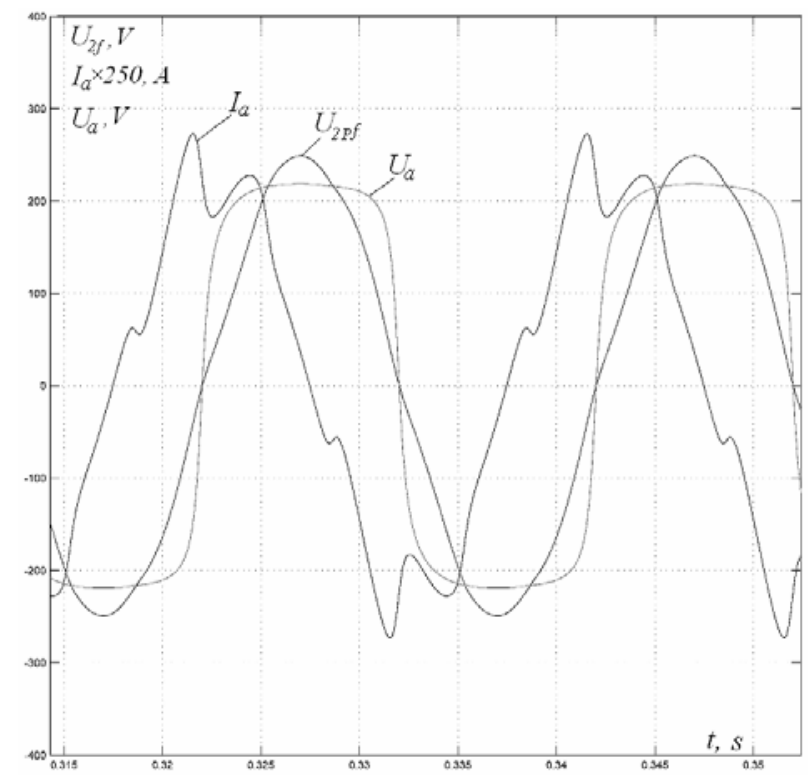

Fig. 8. Temporal dependences of the quasi-stationary process of the change of voltage $u_{a}(t)$, current $i_{a}(t)$ of the arc and voltage $u_{2 p f}(t)$ of the FTU

On computer models, we also investigated the modes of working out the asymmetrically in the phases deterministic perturbations along the lengths of arcs modes of one- and two-phase short circuits and breakdowns of the arc and determined their respective indicators of the quality of the dynamics.

So, Fig. 9 shows the obtained processes of changing the current values of voltage $U_{a}(t)$, current $I_{a}(t)$, arc and current $I_{m}(t)$, and the speed $\omega_{m}(t)$ of the motor of the electric drive of the mechanism of displacement the electrode in all three phases at working out the short circuit in the phase A for a differential control law of the lengths of arcs.

Fig. 10 shows obtained on the developed Simulink model the temporal dependences of the same EM coordinates in each of the phases of the power circuit of the DSP-200 furnace and the motor of the electric drive of the MED of the arc power regulator ARDM-T-12 in the mode of working out of the extreme (symmetrical in phases) of perturbation which leads to a three-phase breakdown of arcs. Analysis of the temporal dependences shown in Fig. 9, 10 shows the oscillating nature of the processes of working out the specified deterministic extreme disturbances with the regulation time of $1.2 \mathrm{~s}$ and $1.4 \mathrm{~s}$, respectively.

In addition to the differential law, other laws of the formation of a control signal on the displacement of electrodes were also investigated. Fig. 11 shows obtained on the model the temporal dependences of the change in the coordinates of the EM (voltage $U_{a}(t)$, current $I_{a}(t)$, arc) of the arc furnace DSP-200 and the coordinate of the motor of the mechanism of the displacement of the electrode (current $I_{m}(t)$, speed $\omega_{m}(t)$ for each of the phases) at working out of the breakdown of the arc in the phase A and regulation by the law of deviation of the arc voltage from the given $U_{d i s}=k\left(U_{\text {a.set }}-U_{a}\right)$. 

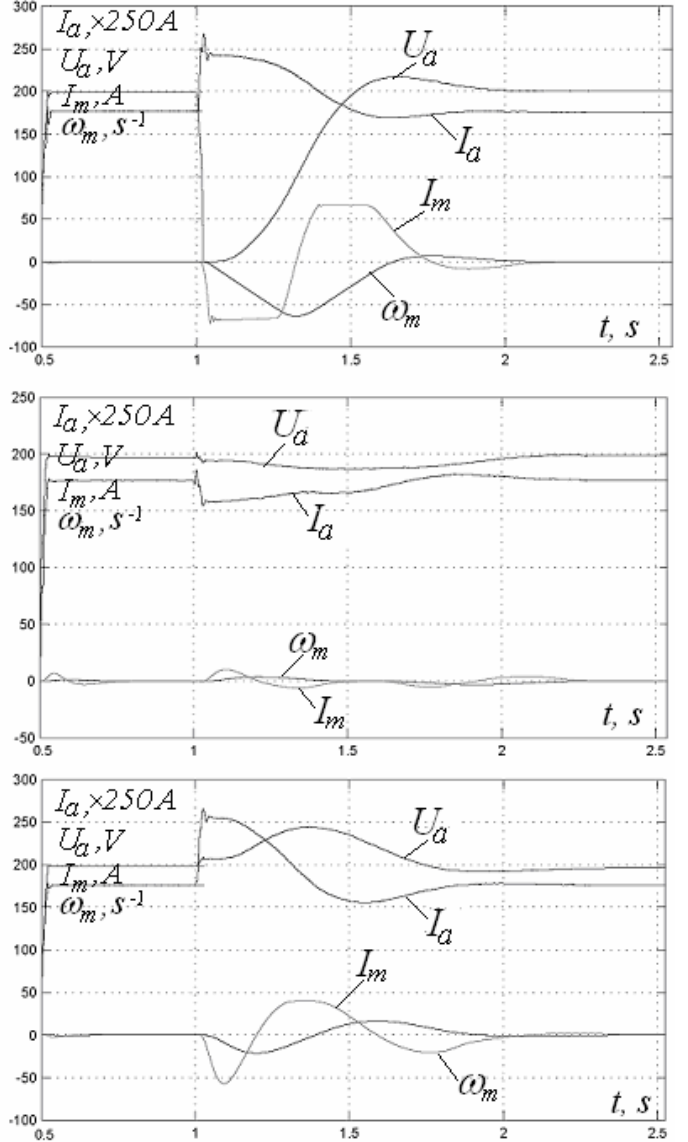

Fig. 9. Temporal dependences of the coordinates of the EM of the furnace DSP-200 and the motor of the MED in each phase at working out the short circuit in the phase A

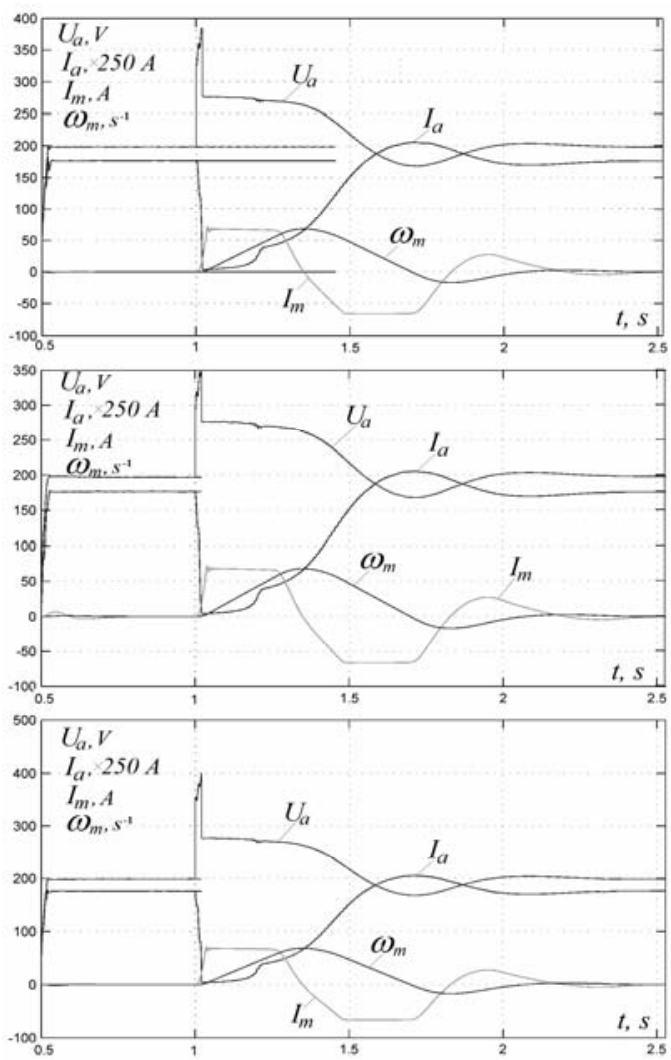

Fig. 10. Temporal dependences of voltage $U_{a}(t)$, current $I_{a}(t)$ of the arc of the furnace DSP-200 and current $I_{m}(t)$ and the speed of the motor $\omega_{m}(t)$ of the MED of each phase at working out of the three-phase breakdowns of the arc
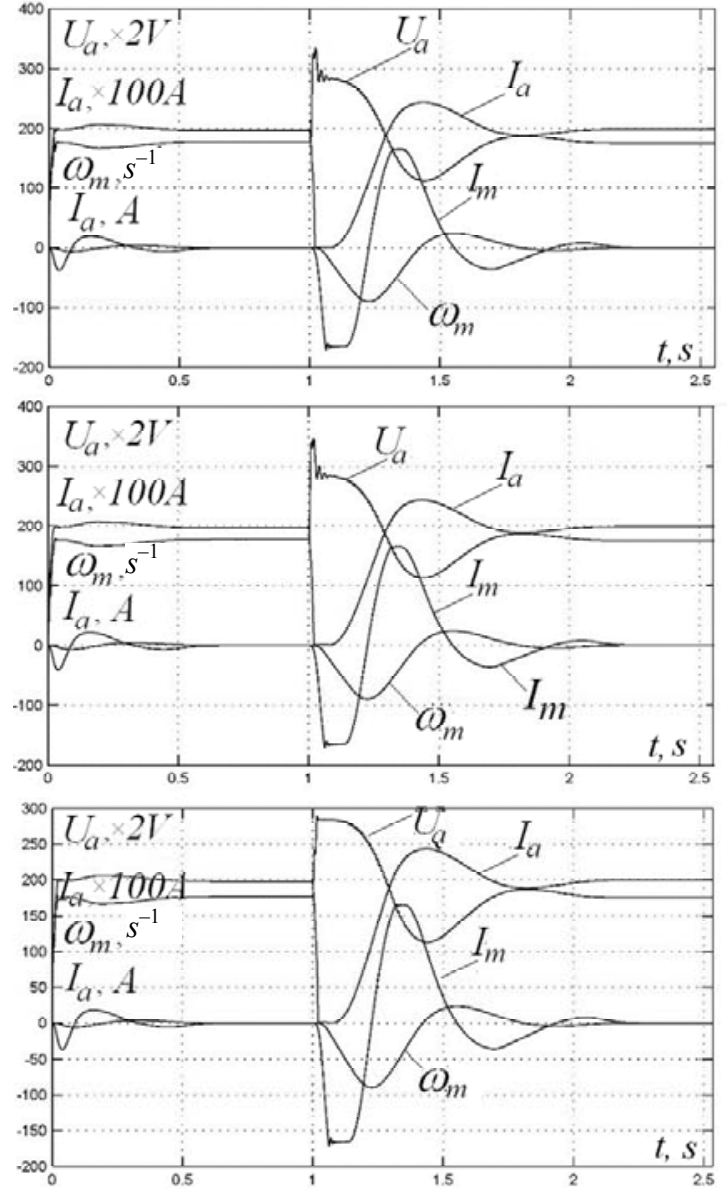

Fig. 11. Changing of the coordinates of the EM $U_{a}(t), I_{a}(t)$ of the furnace DSP-200 and the motor of the MED $I_{m}(t) \omega_{m}(t)$ of the regulator ARDM-T-12 at working out of the breakdowns of the arc in the phase A by the law of the arc voltage deviation

The main perturbations in the process of melting of charge in an arc furnace are stationary random perturbations along the arc length stochastic characteristics of which vary during melting. With the occasional nature the voltage on the power supply buses of the arc furnace also fluctuates, and also the parameters of the elements of the power circuit (elements of the furnace's short network) also accidentally change, and so on.

To reproduce in the compiled Simulink model the random processes of coordinate and parametric disturbances mentioned above, a module for the generation of three independent implementations of random processes with identical stochastic characteristics and the possibility of changing their parameters in correspondence with the characteristics of these perturbations operating in the studied technological melting stages in the operating arc furnace DSP-200 is developed and included to the model.

In the initial stages, the indicated perturbations have the maximum amplitudes in the range of low frequencies $(0.2-1.5 \mathrm{~Hz})$, then the amplitudes decrease, and their frequencies increase, and in the stage of oxidation and refining (in particular the stage of boiling of the slag), the amplitudes are minimal, and their frequencies lie in the band of 5-8 Hz. In the developed module of the generation of random perturbations, the possibility of such a change in their parameters in accordance with the 
values of the parameters of stochastic characteristics of real disturbances in the investigated technological stages of melting is realized. A fragment of such random perturbations for the technological stage of fusing wells in the arc furnace DSP-200 is shown in Fig. 12.

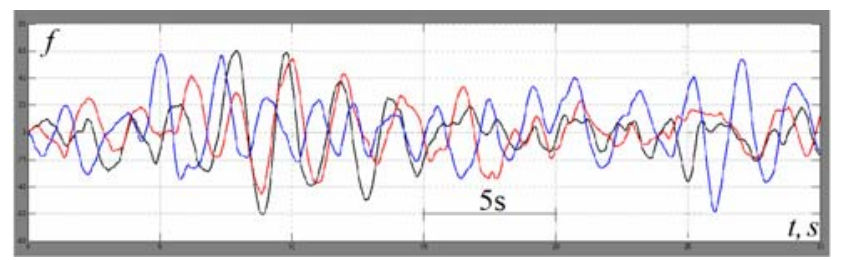

Fig. 12. A fragment of random perturbations along the lengths of $\operatorname{arcs} f(t)$ in three phases at the stage of wells fusing

As an example, Fig. 13 shows the obtained on the developed structural Simulink model at the action of stationary random perturbations along the arc lengths the processes of changing the arcs currents at the working out by the power regulator of the type ARDM-T-12 of stochastic perturbations in each phase during the technological period of boiling of the slag and under the control by the differential law.

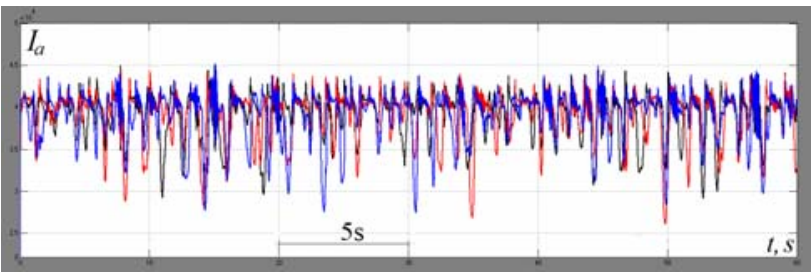

Fig. 13. Temporal dependences of change of currents of arcs $I_{a}(t)$ of the arc furnace DSP-200 during the technological period of boiling of slag at operation of the regulator ARDM-T-12 (differential law)

On the created Simulink-model, mathematical experiments were conducted to study the dynamical indicators at using each of the above-mentioned control laws in the single-circuit ACS (ARDM-T-12 regulator), as well as at the joint action of the electromechanical circuit (ARDM-T-12 arc power regulator) and only highspeed electric circuit for regulating arcs currents (twocircuit structure of ACS [11]) under the action of both deterministic and stationary random coordinate and parametric perturbations in each phase.

As an example, Fig. 14 shows the results of the performed mathematical experiments on the study of the process of working out of deterministic perturbations which resulted in a symmetrical three-phase short circuit in the DSP-200 furnace only at operation of the electromechanical circuit with a differential control law. (Fig. 14,a); only high-speed electric circuit (Fig. 14,b) and in the case of joint operation of both circuits (twocircuit ACS, Fig. 14,c). As can be seen from the processes shown in Fig. 14, at the use of one-circuit ACS (electromechanical circuit - ARDMT-T-12 arcs power regulator), the time of regulating arcs currents is $t_{\text {reg }}=1.65 \mathrm{~s}$, at operating the high-speed circuit $t_{\text {reg }}=0.05 \mathrm{~s}$, and for the two-circuit ACS $t_{\text {reg }}=0.125 \mathrm{~s}$. Some increase in the time of regulation in the two-circuit ACS is due to the asymmetry of the dynamics of the regulation of the electromechanical circuit through the phase-phase asymmetry of the parameters of the power elements of the short network of the arc furnace DSP-200.

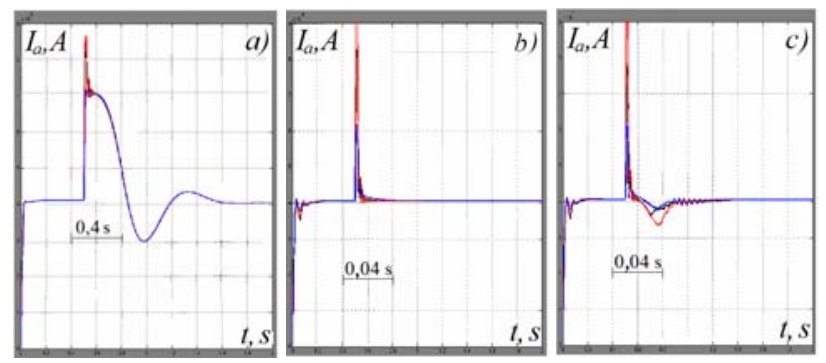

Fig. 14. Arcs currents $I_{a}(t)$ in three phases at the symmetrical short circuit of the arc DSP-200 and operating ARDM-T-12 (a); only high-speed circuit (b); and two-circuit ACS (c)

Practical interest is the indicators of dynamics of the two-circuit ACS of the electric mode of the DSP-200 in the working out of stationary accidental perturbations along the arc length in different stages of melting, since such disturbances are the main ones on each smelt. That is why on the created Simulink model, a number of mathematical experiments were conducted to study the indicators of the dynamics of the regulation of the EM coordinates, indicators of energy efficiency and electromagnetic compatibility. The purpose of these studies was to obtain integral assessments of the quality of dynamics, in particular the value of the dispersion of currents (voltages, powers) of arcs and indicators of electromagnetic compatibility of arc furnace modes and a network in the operation of a two-circuit ACS, as the most perfect in terms of energy efficiency and, for comparison, the indicators of the other two structures of ACS of the electric modes under the influence of stationary random perturbations in different technological stages of melting.

As an example, Fig. 15, 16 show the temporal dependences of disturbances (Fig. 15, $a$ and Fig. 16, $a$ ) and their corresponding temporal arcs currents dependences (Fig 15,b and Fig. 16,b) in three phases corresponding to the technological stages of wells collapse and meltdown of a solid charge (Fig. 15 and Fig. 16, respectively), in the operation of the two-circuit system for automatic regulation of arcs currents of the arc furnace DSP-200.

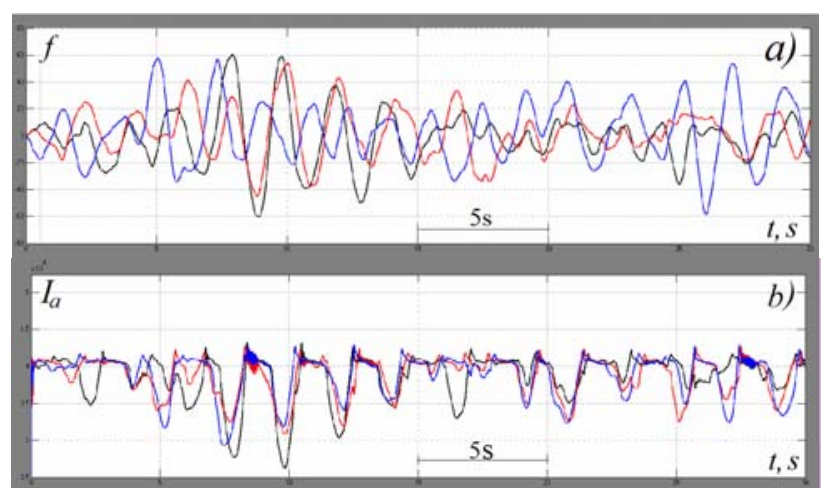

Fig. 15. Perturbations along the lengths of the $\operatorname{arcs} f(t)$ in phases $(a)$ and the corresponding currents of the $\operatorname{arcs} I_{a}(t)(b)$ of the two-circuit ACS at the technological stage of wells collapse

In Table 2 average in phases the values of the dispersions of arcs currents obtained in computer 
experiments under the action in arc gaps of the same realizations of three-phase disturbances along the arcs lengths for the same technological stage but at the functioning of different structures of the ACS of the EM of the DSP-200 are presented.

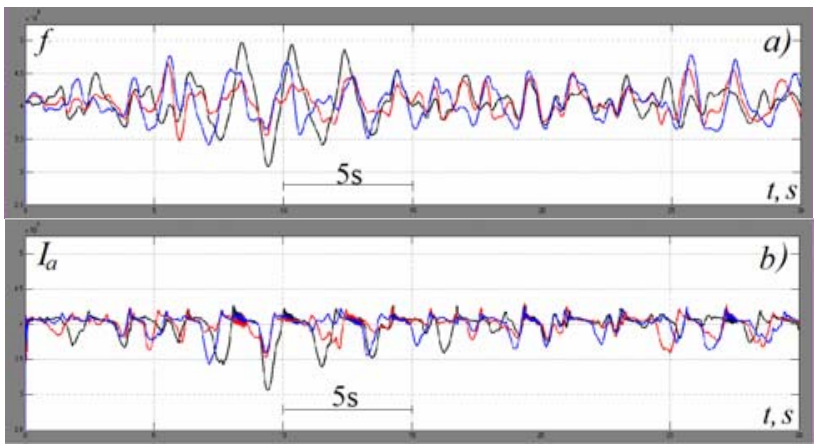

Fig. 16. Perturbations along the lengths of the $\operatorname{arcs} f(t)$ in phases (a) and the corresponding currents of the $\operatorname{arcs} I_{a}(t)(b)$ of the two-circuit ACS at the technological stage of meltdown of a solid charge

Table 2

Average over the phases the values of the dispersion of the arcs currents of the DSP-200 furnace for different ACS and different technological stages

\begin{tabular}{|l|c|c|c|c|}
\hline \multirow{2}{*}{$\begin{array}{c}\text { ACS } \\
\text { structure }\end{array}$} & \multicolumn{4}{|c|}{ Technological stage } \\
\cline { 2 - 5 } & $\begin{array}{c}\text { Start of } \\
\text { melting, } \\
\mathrm{kA}^{2}\end{array}$ & $\begin{array}{c}\text { Wells } \\
\text { melting, } \\
\mathrm{kA}^{2}\end{array}$ & $\begin{array}{c}\text { Oxidation, } \\
\mathrm{kA}^{2}\end{array}$ & $\begin{array}{c}\text { Refinement, } \\
\mathrm{kA}^{2}\end{array}$ \\
\hline $\begin{array}{l}\text { One-circuit } \\
\text { (ARDM-T- } \\
\text { 12) }\end{array}$ & 26.0 & 40 & 29.0 & 6.8 \\
\hline $\begin{array}{l}\text { High-speed } \\
\text { circuit }\end{array}$ & 13.0 & 16.5 & 6.9 & 2.2 \\
\hline Two-circuit & 9.5 & 8.2 & 6.7 & 2.0 \\
\hline
\end{tabular}

The analysis of presented in the Table 2 values of dispersions of arcs currents shows that the use in the control system structure of the high-speed electric circuit of regulating arcs currents allows to significantly reduce the dispersion of currents by 2.5-5 times.

Due to the increase of the speed of regulation of arcs currents in the two-circuit structure of the ACS, the phase autonomy (symmetry) of arcs currents regulation, active and reactive powers, as well as the indicators of energy efficiency and electromagnetic compatibility of the arc furnace modes and the network are improved. Table 3 shows the results obtained from model research on the developed Simulink model of integrated estimates of some indicators of electromagnetic compatibility of arc furnace DSP-200 modes and the power supply network.

Table 3

Average in phases indicators of electromagnetic compatibility of the arc furnace DSP-200 during the period of charge melting

\begin{tabular}{|c|c|c|}
\hline \multirow{2}{*}{ Functioning indexes } & \multicolumn{2}{|c|}{ ACS structures } \\
\cline { 2 - 3 } & One-circuit ACS & Two-circuit ACS \\
\hline$C_{\text {thd }}$ & 0.096 & 0.081 \\
\hline $\cos \varphi$ & 0.82 & 0.89 \\
\hline$\delta U_{s s}, \%$ & 1.42 & 0.92 \\
\hline$F$ & 0.168 & 0.058 \\
\hline
\end{tabular}

The analysis of the obtained estimates of the parameters of the electromagnetic compatibility of the modes of the DSP-200 furnace and the power supply network at various technological stages of melting showed that the coefficient of distortion of the sinusoidal currents of the power supply network $C_{t h d}$ in the operation of the two-circuit ACS compared with the operation of a one-circuit one (power regulator ARDMT-12) decreases by $12-20 \%$, the coefficient of power $\cos \varphi$ in the operation of the two-circuit ACS increases by $6-10 \%$, the voltage fluctuations of the power supply network $\delta U_{s s}$ of the furnace thus decreases by $30-40 \%$, while the dose of the flicker $F$-by $48-65 \%$.

At the same time, due to the significant improvement of the dynamics of arcs currents regulation (reducing the dispersion of arcs currents), in the operation of a two-circuit ACS, the power of electrical losses in a furnace's short network decreases, including for the account of reduced reactive power consumption, respectively the electrical efficiency improves, the dispersion of the arcs power decreases and the uniformity in time and in phases (along the perimeter of the melt) of the input of active power into the furnace improves (thereby melt is more uniformly heating up and, accordingly, the local overheating of the melt and the side walls of the furnace masonry are eliminated). Increasing the speed of regulation of arcs currents positively affects the alignment of the phase loads of the furnace and as a result, the negative effect of the "wild» and «dead» phase is practically eliminated or significantly weakened, as well as the coefficient of phase asymmetry of the electrical supply network voltage is reduced.

\section{Conclusions.}

1. Based on the application of the statistic M-criterion of Bartlett it is shown that the created three-phase in instantaneous coordinates Simulink model has sufficient accuracy (adequacy) of the reproduction of the processes of changing arcs currents.

2. Created on the basis of a combination of typical elements of the Simulink application library and SimPowerSystems blocks of the Matlab software, the structured Simulink model of an arc furnace has a convenient setup interface for studying the dynamics indices of the EM and the electromagnetic compatibility indices for different structures and parameters of the ACS and the power circuit of the power supply of three-phase arcs, control laws, dependencies of dynamic volt-ampere characteristics of arcs and parameters of stochastic characteristics of perturbations.

3. Obtained values of quality indicators of dynamics of the investigated structures of the ACS of the EM of the arc furnace DSP-200 have shown that the best indicators of the dynamics inherent in two-circuit control system: compared with one-circuit system (arcs power regulator ARDM-T) the regulation time of arcs currents at working out of extreme disturbances of the electric mode (shortcircuit and breakdowns of the arc) using a high-speed circuit in the structure of a two-circuit ACS decreases 20-40 times, and the arcs currents dispersion at working 
out the random disturbances at other similar conditions decreases 3-5 times, as well as performance indicators of the electromagnetic compatibility of modes of the arc furnace and power supply network are significantly improved.

\section{REFERENCES}

1. Wang Y., Mao Z., Tian H., Li Y., Yuan P. Modeling of electrode system for three-phase electric arc furnace. Journal of Central South University of Technology, 2010, vol.17, no.3, pp. 560-565. doi: 10.1007/s11771-010-0523-3.

2. Paranchuk Y.S. Modeling and research of electric arc furnace current regulation system modes. Bulletin of Lviv Polytechnic National University. Series: «Electrical and electromechanical systems», 2000, no.403, pp. 126-133. (Ukr). 3. Lozynskyy O.Y., Paranchuk Y.S., Lozynskyy A.O., Maruschak Y.Y. Mathematical model of power supply system and modes control of the EAF-PSN electrotechnology complex. Scientific Bulletin of the National Mining University, 2004, no.3, pp. 8-15. (Ukr).

4. Varetsky Y., Lozynsky O., Paranchuk Y. A new design of SVC thyristor controlled reactor. Proceedings of the International Conference EPQU'03: «Electrical Power Quality and Utilization». Krakow, Poland, 2003, pp. 353-360.

5. Balan R., Maties V., Hancu O., Stan S., Lapusan C. Simulation of an electric arc furnace electrode position system. Available at: http://www.freepatentsonline.com/article/AnnalsDAAAM-Proceedings/177174488.html (accessed 02 May 2017).

6. Balan R., Maties V., Hancu O., Stan S., Ciprian L. Modeling and control of an electric arc furnace. 2007 Mediterranean Conference on Control \& Automation, Jun. 2007. doi: 10.1109/med.2007.4433737.

7. Rahmatollah Hooshmand, Mahdi Banejad, Mahdi Torabian Esfahanj. A new time domain model for electric arc furnace. Journal of Electrical Engineering, 2008, vol.59, no.4, pp. 195-202.

8. Mahmood Moghadasian, Emad AlNasser. Modelling and control of electrode system for an electric arc furnace. 2nd International Conference on Research in Science, Engineering and Technology (ICRSET'2014), March 21-22, 2014 Dubai (UAE), pp. 129-133. doi: 10.15242/iie.e0314558.

9. Paranchuk Y.S. Modeling of the arcs characteristics and processes in arc steelmaking furnace. Bulletin of Lviv Polytechnic National University. Series: «Electrical and electromechanical systems», 2003, no.487, pp. 108-116. (Ukr).

10. Gaydyshev I. Analiz i obrabotka dannykh: spetsial'nyi spravochnik [Analysis and processing of data: special reference book]. Saint Petersburg, Piter Publ., 2001. 752 p. (Rus).

11. Paranchuk Y.S. Investigation of the two-level reactive power compensation system in networks with arc steelmaking furnaces. Technical electrodynamics. Thematic issue "Power electronics \& energy efficiency», 2004, part 2, pp. 73-78. (Ukr).

Received 20.02.2018

O.Y. Lozynskyi ${ }^{1}$, Doctor of Technical Sciences, Professor,

Y.S. Paranchuk ${ }^{1}$, Doctor of Technical Sciences, Professor,

R.Y. Paranchuk ${ }^{1}$, Candidate of Technical Sciences,

F.D. Matico ${ }^{1}$, Doctor of Technical Sciences, Associate

Professor,

${ }^{1}$ Lviv Polytechnic National University,

12, S. Bandera Str., Lviv, 79013, Ukraine, phone +3802582468

e-mail: yparanchuk@yahoo.com

How to cite this article:

Lozynskyi O.Y., Paranchuk Y.S., Paranchuk R.Y., Matico F.D. Development of methods and means of computer simulation for studying arc furnace electric modes. Electrical engineering \& electromechanics, 2018, no.3, pp. $28-36$. doi: 10.20998/2074-272X.2018.3.04. 